\title{
THERMAL CONDUCTIVITIES OF LIQUID ALCOHOLS AND THEIR BINARY MIXTURES
}

\author{
KOJIRO OGIWARA \\ Department of Industrial Chemistry, Akita Technical College, Akita 011 \\ YASUHIKo ARAI \\ Department of Chemical Engineering, Kyushu University, Fukuoka 812 \\ SHOZABURo SAITO \\ Department of Chemical Engineering, Tohoku University, Sendai 980
}

\begin{abstract}
The thermal conductivities of ten pure liquid alcohols and four of their binary mixtures were measured by use of the relative horizontal parallel-plate method (steady-state type) under atmospheric pressure. Measurements for pure alcohols were carried out at temperatures from 20 to $70^{\circ} \mathrm{C}$ and for binary mixtures at 25.0 and $50.0^{\circ} \mathrm{C}$.

A previous correlation model developed for the thermal conductivities of nonpolar liquids on the basis of the lattice model coupled with the hole theory concept has been successfully extended to polar liquids such as alcohols by the introduction of a new empirical parameter to represent the polar effect. Reduced values of the potential parameters and the empirical parameter, needed in the calculation of thermal conductivities, could be correlated by quadratic functions of Pitzer's acentric factor and Stiel's polar factor. The present model is also extended to alcohol mixtures by use of binary interaction parameters.
\end{abstract}

\section{Introduction}

The thermal conductivity of liquids is an important transport property required in the design and analysis of various heat transfer processes and is also of interest in the clarification of the internal structures of liquids.

The present authors ${ }^{13}$ ) have previously measured the thermal conductivities of seven liquid hydrocarbons (n-paraffins and aromatics) and three of their binary mixtures under atmospheric pressure by using a relative horizontal parallel-plate method (steady-state type) and have proposed a correlation method for the thermal conductivities of liquids and their mixtures on the basis of the lattice model of Horrocks et al. ${ }^{6)}$ coupled with the hole theory concept.

The purposes of this study are to measure the thermal conductivity of liquid alcohols and their binary mixtures and to extend the previous correlation method to polar substances. The thermal conductivities of ten liquid alcohols (ethanol, 1-propanol, 2-propanol, 1-butanol, 2-butanol, 2-methyl-1-propanol, 1-pentanol, 2-methyl-1-butanol, 1-hexanol, and 1-heptanol) were measured at temperatures from 20 to $70^{\circ} \mathrm{C}$ and four of their binary mixtures (ethanol-1-propanol, ethanol-2-butanol, 1-propanol2-butanol, and 2-butanol-1-butanol) were measured at temperatures of 25.0 and $50.0^{\circ} \mathrm{C}$ under atmospheric pressure by the same method as in the previous

\footnotetext{
Received February 2,1982. Correspondence concerning this article should be addressed to $\mathrm{K}$. Ogiwara.
}

study ${ }^{13)}$. The thermal conductivity data obtained here were compared with recent literature values for pure alcohols.

A previous correlation method for thermal conductivity has been found to be applicable to polar substances such as alcohols with the introduction of a new parameter representing the polar effect. Four parameters required in the calculation of thermal conductivities could be correlated with Pitzer's acentric factor and Stiel's polar factor. By use of the binary interaction parameters, the present model is extended to alcohol mixtures.

\section{Experimental}

\section{1 Apparatus and procedure}

The experimental apparatus and procedure used in the present study were almost the same as described in the previous paper ${ }^{13}$. A brief description of the present apparatus and procedure is given below.

The apparatus was of a relative horizontal parallelplate, steady-state type. A glass plate $(260 \times 260 \times 10$ $\mathrm{mm}$ ) was used as a standard material. The thermal conductivity of the standard glass plate was calibrated with distilled water. The value of the thermal conductivity of distilled water recommended by Touloukian et $a l^{19}$ ) was adopted in this study. The uncertainty of this value is estimated to be within $1 \%$. Further, it is ascertained that the thermal conductivity of Touloukian et al. ${ }^{19)}$ coincides with IAPS recommended values ${ }^{20)}$ within $1 \%$. A liquid 
Table 1 Purities and experimental thermal conductivities for pure alcohols

\begin{tabular}{|c|c|c|c|c|c|c|c|c|c|}
\hline \multicolumn{2}{|c|}{ Ethanol $(99.9 \%)$} & \multicolumn{2}{|c|}{ 1-Propanol $(99.9 \%)$} & \multicolumn{2}{|c|}{ 2-Propanol $(99.7 \%)$} & \multicolumn{2}{|c|}{ 1-Butanol $(99.5 \%)$} & \multicolumn{2}{|c|}{ 2-Butanol $(99.8 \%)$} \\
\hline $\begin{array}{c}t \\
{\left[{ }^{\circ} \mathrm{C}\right]}\end{array}$ & {$\left[\mathrm{W} \cdot \mathrm{m}^{-1} \cdot \mathrm{K}^{-1}\right]$} & $\begin{array}{c}t \\
{\left[{ }^{\circ} \mathrm{C}\right]}\end{array}$ & {$\left[\mathrm{W} \cdot \mathrm{m}^{-1} \cdot \mathrm{K}^{-1}\right]$} & $\begin{array}{c}t \\
{\left[{ }^{\circ} \mathrm{C}\right]}\end{array}$ & {$\left[\mathrm{W} \cdot \mathrm{m}^{-1} \cdot \mathrm{K}^{-1}\right]$} & $\begin{array}{c}t \\
{\left[{ }^{\circ} \mathrm{C}\right]}\end{array}$ & {$\left[\mathrm{W} \cdot \mathrm{m}^{-1} \cdot \mathrm{K}^{-1}\right]$} & $\begin{array}{c}t \\
{\left[{ }^{\circ} \mathrm{C}\right]}\end{array}$ & {$\left[\mathrm{W} \cdot \mathrm{m}^{-1} \cdot \mathrm{K}^{-1}\right]$} \\
\hline 20.34 & $0.161_{4}$ & 20.32 & $0.150_{4}$ & 20.03 & $0.133_{B}$ & 20.08 & $0.148_{4}$ & 19.95 & $0.134_{4}$ \\
\hline 25.00 & $0.160_{2}$ & 24.99 & $0.149_{7}$ & 25.01 & $0.132_{3}$ & 25.04 & $0.146_{8}$ & 24.93 & $0.133_{5}$ \\
\hline 30.04 & $0.159_{8}$ & 30.08 & $0.149_{2}$ & 30.03 & $0.131_{\mathrm{g}}$ & 30.01 & $0.145_{6}$ & 30.28 & $0.133_{0}$ \\
\hline 35.03 & $0.158_{8}$ & 35.08 & $0.148_{1}$ & 35.09 & $0.130_{6}$ & 35.01 & $0.144_{8}$ & 35.05 & $0.132_{4}$ \\
\hline 40.03 & $0.157_{8}$ & 40.07 & $0.147_{3}$ & 39.96 & $0.129_{7}$ & 39.94 & $0.144_{0}$ & 40.00 & $0.131_{7}$ \\
\hline 44.95 & $0.156_{9}$ & 45.00 & $0.146_{5}$ & 44.91 & $0.128_{7}$ & 44.90 & $0.143_{5}$ & 44.98 & $0.131_{1}$ \\
\hline 49.96 & $0.155_{9}$ & 50.00 & $0.145_{6}$ & 49.93 & $0.127_{4}$ & 49.98 & $0.142_{8}$ & 49.99 & $0.129_{6}$ \\
\hline \multirow[t]{3}{*}{54.96} & $0.155_{1}$ & 54.99 & $0.144_{3}$ & & & 55.00 & $0.142_{6}$ & 55.00 & $0.129_{3}$ \\
\hline & & 60.10 & $0.143_{3}$ & & & 59.93 & $0.141_{s}$ & 62.76 & $0.128_{5}$ \\
\hline & & 65.01 & $0.142_{9}$ & & & 65.03 & $0.140_{0}$ & 67.74 & $0.127_{8}$ \\
\hline & \multicolumn{2}{|c|}{ 1-Pentanol $(99.5 \%)$} & \multicolumn{2}{|c|}{$\begin{array}{c}\text { 2-Methyl-1- } \\
\text { butanol }(99.6 \%) \\
t\end{array}$} & \multicolumn{2}{|c|}{ 1-Hexanol $(98.6 \%)$} & \multicolumn{2}{|c|}{ 1-Heptanol $(98.7 \%)$} \\
\hline $\begin{array}{c}t \\
{\left[{ }^{\circ} \mathrm{C}\right]}\end{array}$ & {$\left[\mathrm{W} \cdot \mathrm{m}^{-1} \cdot \mathrm{K}^{-1}\right]$} & $\stackrel{t}{\left.{ }^{\circ} \mathrm{C}\right]}$ & {$\left[\mathrm{W} \cdot \stackrel{\lambda}{\left.\mathrm{m}^{-1} \cdot \mathrm{K}^{-1}\right]}\right.$} & $\begin{array}{c}t \\
{\left[{ }^{\circ} \mathrm{C}\right]}\end{array}$ & {$\left[\mathrm{W} \cdot \mathrm{m}^{-1} \cdot \mathrm{K}^{-1}\right]$} & $\begin{array}{c}t \\
{\left[{ }^{\circ} \mathrm{C}\right]}\end{array}$ & $\stackrel{\lambda}{\left.\stackrel{\lambda}{\mathrm{W}} \cdot \mathrm{m}^{-1} \cdot \mathrm{K}^{-1}\right]}$ & $\stackrel{t}{\left[{ }^{\circ} \mathrm{C}\right]}$ & {$\left[\mathrm{W} \cdot \stackrel{\lambda}{\mathrm{m}^{-1}} \cdot \mathrm{K}^{-1}\right]$} \\
\hline 20.09 & $0.131_{5}$ & 20.20 & $0.148_{5}$ & 20.07 & $0.135_{2}$ & 20.07 & $0.149_{8}$ & 20.09 & $0.151_{4}$ \\
\hline 25.07 & $0.130_{9}$ & 25.05 & $0.147_{7}$ & 25.04 & $0.134_{5}$ & 25.05 & $0.149_{1}$ & 25.06 & $0.151_{0}$ \\
\hline 30.08 & $0.130_{4}$ & 30.06 & $0.147_{1}$ & 30.04 & $0.133_{9}$ & 30.04 & $0.148_{5}$ & 30.05 & $0.150_{0}$ \\
\hline 35.06 & $0.129_{7}$ & 35.03 & $0.146_{4}$ & 35.06 & $0.133_{4}$ & 35.03 & $0.147_{8}$ & 35.05 & $0.149_{7}$ \\
\hline 40.05 & $0.129_{0}$ & 39.98 & $0.145_{\varsigma}$ & 39.97 & $0.132_{7}$ & 39.99 & $0.147_{1}$ & 39.98 & $0.148_{8}$ \\
\hline 45.03 & $0.128_{3}$ & 44.97 & $0.144_{8}$ & 44.96 & $0.132_{1}$ & 44.99 & $0.146_{5}$ & 44.99 & $0.148_{2}$ \\
\hline 50.01 & $0.127_{8}$ & 49.97 & $0.144_{3}$ & 49.96 & $0.131_{8}$ & 49.96 & $0.145_{7}$ & 49.98 & $0.147_{5}$ \\
\hline 54.52 & $0.127_{2}$ & 54.97 & $0.143_{3}$ & 54.96 & $0.131_{0}$ & 54.99 & $0.145_{0}$ & 54.97 & $0.147_{0}$ \\
\hline 60.08 & $0.126_{7}$ & 62.75 & $0.142_{1}$ & 62.74 & $0.130_{1}$ & 62.76 & $0.144_{2}$ & 62.70 & $0.145_{\theta}$ \\
\hline 65.08 & $0.126_{2}$ & 67.72 & $0.141_{4}$ & 67.71 & $0.129_{b}$ & 67.68 & $0.143_{2}$ & 67.68 & $0.145_{6}$ \\
\hline
\end{tabular}

sample was held between standard glass plates. By circulating water at constant temperature (controlled within $\pm 0.01^{\circ} \mathrm{C}$ ) through the jackets, a temperature gradient was established in the test liquid close to the desired experimental temperature. As hightemperature water was circulated through the upper jacket, heat flux was directed downward in order to minimize heat transfer by convection.

Copper-constantan thermocouples $(0.07 \mathrm{~mm}$ in diameter) were provided to measure the temperature gradients across the liquid layer and the standard glass plates.

The accuracy of temperature measurement by the calibrated thermocouple is believed to be within $\pm 0.04^{\circ} \mathrm{C}$.

Liquid samples were prepared by boiling to evolve gas. About 2 hours was required to reach a steady thermal state, since constant-temperature water was being circulated. Then, the thermal conductivity of a liquid sample $\lambda$ could be obtained as

$$
\lambda=\lambda_{0}\left(d / d_{0}\right)\left(\Delta t_{0} / \Delta t\right)
$$

where $\lambda_{0}, d_{0}$, and $\Delta t_{0}$ are the thermal conductivity, the thickness and the temperature gradient of the standard glass plate, and $d$ and $\Delta t$ are the thickness and temperature gradient of the liquid sample, respectively. The thermal conductivity of the standard glass plate was preliminarily determined and could be represented by a linear function of temperature.

$$
\lambda_{0}=0.9966(1+0.00188 t)
$$

The reproducibility of the thermal conductivity in the present measurements is within $1 \%$. The maximum uncertainty of the present thermal conductivity finally obtained is estimated to be within $2 \%$.

\section{2 Materials}

Alcohols used in this study were guaranteed reagents supplied by Nakarai Chemicals, Ltd. Their purities, determined by gas chromatography, are shown in Table 1. These alcohols were used without further purification.

\section{Experimental Results}

The thermal conductivities of pure alcohols have been determined at several temperatures and are shown in Table 1 and Fig. 1. All of the present data can be expressed as a linear function of temperature.

$$
\lambda=A+B t
$$

The values of the coefficients and the average error between experimental and calculated thermal conductivities are presented in Table 2.

The thermal conductivities of pure liquid alcohols were recently measured by several workers. Raal et $a .^{15}{ }^{15}$ presented the thermal conductivities and their temperature coefficients for ten normal alcohols from methanol to decanol for a temperature range of -20 to $80^{\circ} \mathrm{C}$ using the relative strain-compensated hotwire method. All of the data of Raal et al. ${ }^{15}$ are higher than the present data by about $4-6 \%$. Nagashima et al. ${ }^{12)}$ measured the thermal con- 
Table 2 Coefficients in Eq. (3) for pure alcohols

\begin{tabular}{|c|c|c|c|c|c|}
\hline No. & \multicolumn{2}{|c|}{ Alcohol } & $A$ & $B \times 10^{3}$ & $\begin{array}{l}\text { Avg. } \\
\text { error }[\%]^{*}\end{array}$ \\
\hline 1 & \multicolumn{2}{|c|}{ Ethanol } & 0.1650 & -0.181 & 0.06 \\
\hline 2 & \multicolumn{2}{|c|}{ 1-Propanol } & 0.1542 & -0.176 & 0.12 \\
\hline 3 & \multicolumn{2}{|c|}{ 2-Propanol } & 0.1376 & -0.201 & 0.13 \\
\hline 4 & \multicolumn{2}{|c|}{ 1-Butanol } & 0.1507 & -0.159 & 0.26 \\
\hline 5 & \multicolumn{2}{|c|}{ 2-Butanol } & 0.1372 & -0.140 & 0.12 \\
\hline 6 & \multicolumn{2}{|c|}{ 2-Methyl-1-propanol } & 0.1339 & -0.121 & 0.06 \\
\hline 7 & \multicolumn{2}{|c|}{ 1-Pentanol } & 0.1515 & -0.149 & 0.04 \\
\hline 8 & \multicolumn{2}{|c|}{ 2-Methyl-1-butanol } & 0.1375 & -0.118 & 0.05 \\
\hline 9 & \multicolumn{2}{|c|}{ 1-Hexanol } & 0.1526 & -0.136 & 0.06 \\
\hline 10 & \multicolumn{2}{|c|}{ 1-Heptanol } & 0.1540 & -0.127 & 0.09 \\
\hline \multicolumn{6}{|c|}{$\begin{array}{l}* \text { Avg. error }=\left\{\sum\left|\lambda_{\text {expt1. }}-\lambda_{\text {calcd. }}\right| \times 100 / \lambda_{\text {expt1. }}\right\} / N ; N=\text { num- } \\
\text { ber of data }\end{array}$} \\
\hline \multicolumn{6}{|c|}{$\begin{array}{l}\text { Table } 3 \text { Thermal conductivity and density of ethanol-1- } \\
\text { pentanol binary mixtures }\end{array}$} \\
\hline \multirow{2}{*}{\multicolumn{2}{|c|}{$\begin{array}{l}\text { Ethanol } \\
\text { mole } \\
\text { fraction }\end{array}$}} & \multicolumn{2}{|c|}{$\tilde{\lambda}\left[\mathrm{W} \cdot \mathrm{m}^{-1} \cdot \mathrm{K}^{-1}\right]$} & \multicolumn{2}{|c|}{$\tilde{\rho}\left[\mathrm{kg} \cdot \mathrm{m}^{-3}\right\rceil$} \\
\hline & & $25.0^{\circ} \mathrm{C} \quad 5$ & $50.0^{\circ} \mathrm{C}$ & $25.0^{\circ} \mathrm{C}$ & $50.0^{\circ} \mathrm{C}$ \\
\hline & & $0.147_{7}$ & $0.144_{3}$ & 811.4 & 792.5 \\
\hline & & $0.148_{4}$ & $0.144_{5}$ & 808.8 & 789.4 \\
\hline & & $0.150_{5}$ & $0.146_{8}$ & 804.4 & 784.8 \\
\hline & & $0.153_{2}$ & $0.148_{8}$ & 799.5 & 779.3 \\
\hline & & $0.156_{5}$ & $0.151_{\theta}$ & 793.5 & 771.8 \\
\hline & & $0.160_{2}$ & $0.155_{9}$ & 785.3 & 763.6 \\
\hline
\end{tabular}

ductivities of methanol in a temperature range of 0 to $30^{\circ} \mathrm{C}$ and ethanol from -82 to $50^{\circ} \mathrm{C}$ by the transient hot-wire method under atmospheric pressure. The data for ethanol of Nagashima et al. ${ }^{12)}$ are higher than the present data by about $4 \%$. Mallan et al..$^{10}$ determined the thermal conductivities of six alcohols (methanol, ethanol, 1-propanol, 2-propanol, 1-butanol, and 2-butanol) between 20 to $120^{\circ} \mathrm{C}$ at a pressure of $7.5 \mathrm{~atm}$ in relative, transient equipment and also reported that no significant difference was detected between data at $7.5 \mathrm{~atm}$ and $1.0 \mathrm{~atm}$. The data of ethanol, 1-propanol, and 2-propanol obtained by Mallan et al. ${ }^{10)}$ are higher than those of the present study by $2-4 \%$, but the data of 1-butanol and $2-$ butanol are about $2 \%$ lower than the present data. Jobst $^{7}$ ) measured the thermal conductivities of several normal alcohols at temperatures of -100 to $200^{\circ} \mathrm{C}$ by using an absolute unsteady-state method. The present data for ethanol, 1-propanol, and 1-butanol agree well with Jobst's data ${ }^{7)}$. Yaws et al. ${ }^{21}$ presented empirical equations of thermal conductivities for methanol, ethanol, 1-propanol, and 1-butanol. The calculated values by these equations are higher than those of the present study by $2-4 \%$. The recommended thermal conductivity data for pure alcohols are published by ESDU ${ }^{3}$. These data agree with the present data within about $\pm 3 \%$.

Comparisons between the present data and literature values for ethanol are shown in Fig. 2 as an example.

The thermal conductivities of four binary mixtures have been measured at temperatures of 25.0 and

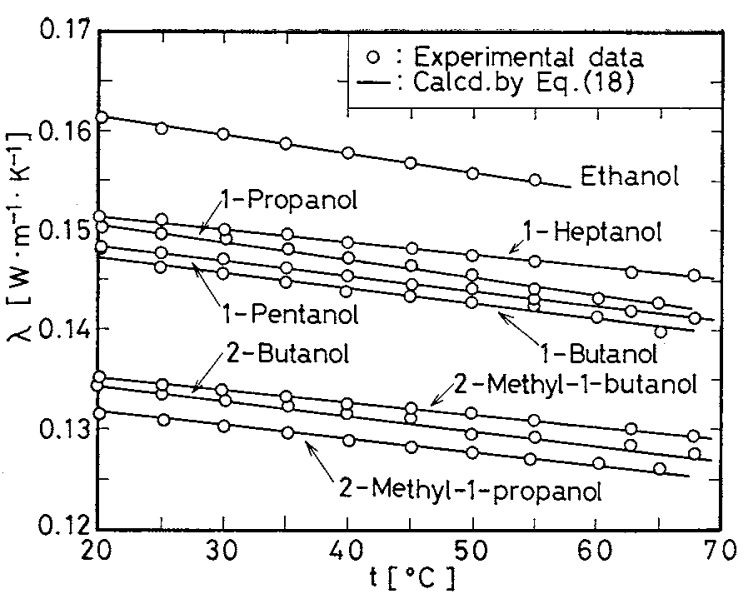

Fig. 1 Thermal conductivity of pure alcohols

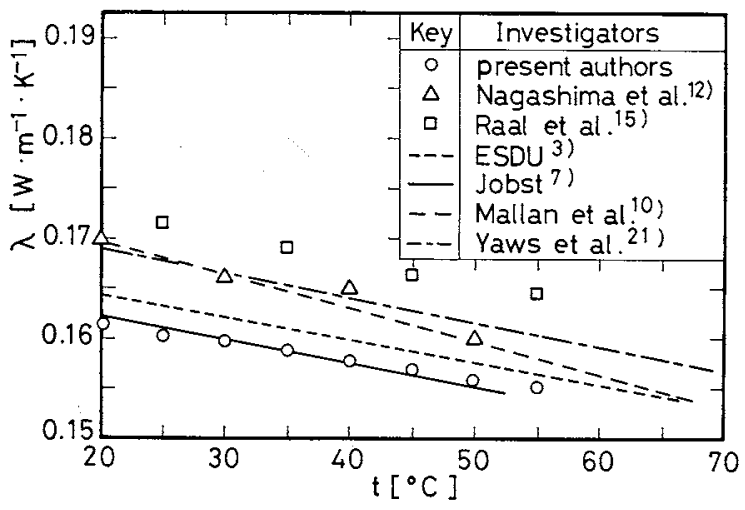

Fig. 2 Comparison of present study with those of other investigators for ethanol

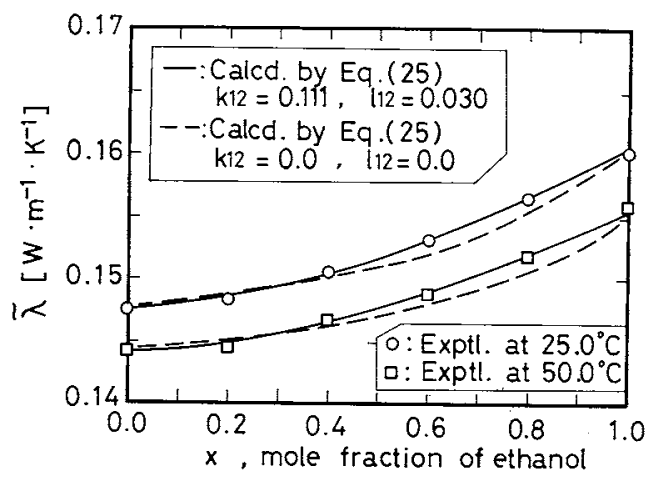

Fig. 3 Thermal conductivity of ethanol-1pentanol binary mixture

$50.0^{\circ} \mathrm{C}$ and are presented in Tables 3 to 6 and Figs. 3 to 6 .

The densities of mixtures investigated in the present study were measured by use of a Wadon-type pycnometer (about $50 \mathrm{~cm}^{3}$ in volume) at temperatures from 20 to $70^{\circ} \mathrm{C}$ under atmospheric pressure because the density data were required in the proposed model to correlate the thermal conductivities. The densities of pure alcohols were reported in previous papers ${ }^{4,14}$. 


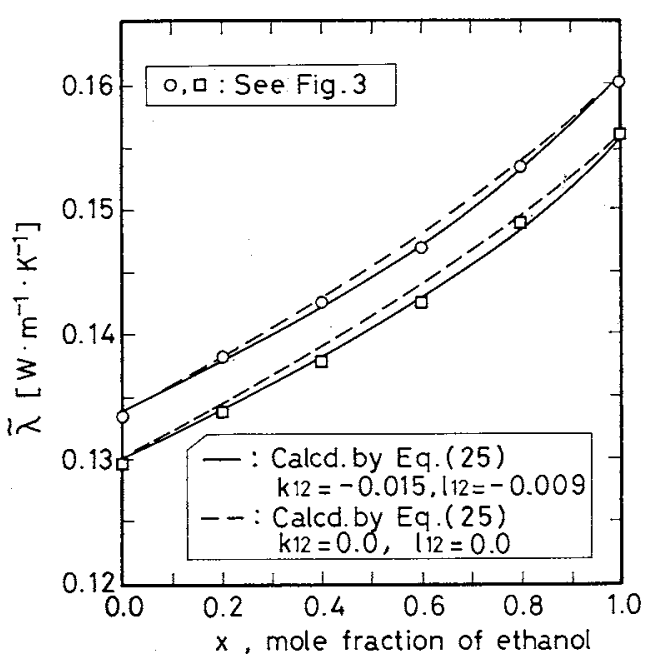

Fig. 4 Thermal conductivity of ethanol-2butanol binary mixture

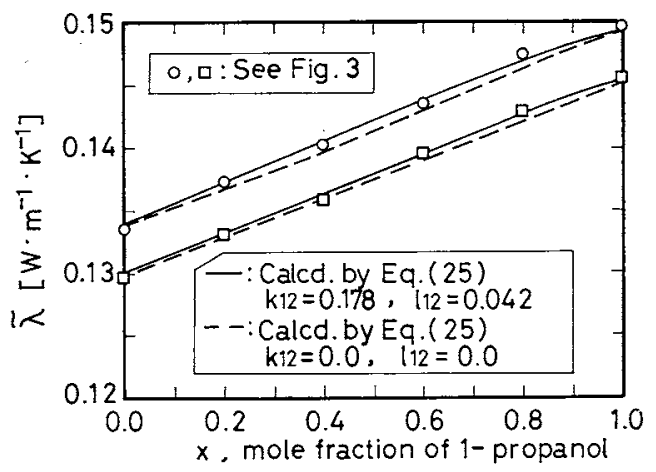

Fig. 5 Thermal conductivity of 1-propanol-2butanol binary mixture

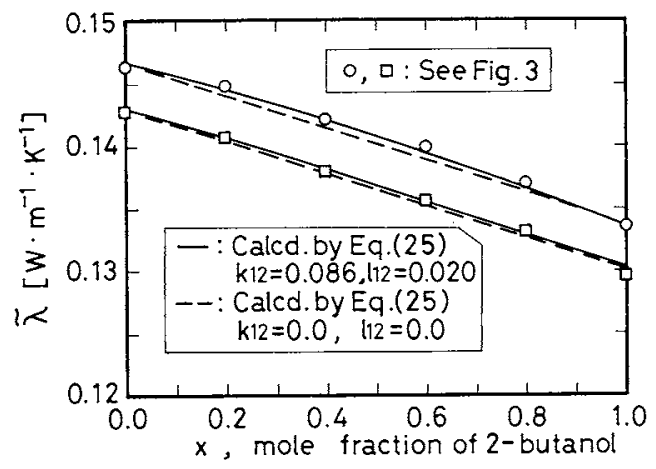

Fig. 6 Thermal conductivity of 2-butanol-1butanol binary mixture

\section{Correlation of Thermal Conductivities of Liquid Alcohols}

\section{1 Working equation}

The liquid structure is approximately assumed to be a face-centered cubic lattice. As heat conduction in liquids can be considered to be caused mainly by the vibrations of molecules, the following equation was proposed ${ }^{6)}$ to predict the thermal conductivity
Table 4 Thermal conductivity and density of ethanol-2butanol binary mixtures

\begin{tabular}{ccccc}
$\begin{array}{c}\text { Ethanol } \\
\text { mole } \\
\text { fraction }\end{array}$ & \multicolumn{2}{c}{$\tilde{\lambda}\left[\mathrm{W} \cdot \mathrm{m}^{-1} \cdot \mathrm{K}^{-1}\right]$} & \multicolumn{2}{c}{$\tilde{\rho}\left[\mathrm{kg} \cdot \mathrm{m}^{-3}\right]$} \\
& $25.0^{\circ} \mathrm{C}$ & $50.0^{\circ} \mathrm{C}$ & $25.0^{\circ} \mathrm{C}$ & $50.0^{\circ} \mathrm{C}$ \\
\hline 0.0 & $0.133_{5}$ & $0.129_{6}$ & 802.5 & 781.2 \\
0.2 & $0.138_{2}$ & $0.133_{8}$ & 800.0 & 778.8 \\
0.4 & $0.142_{5}$ & $0.137_{7}$ & 797.3 & 776.3 \\
0.6 & $0.146_{8}$ & $0.142_{8}$ & 794.0 & 773.0 \\
0.8 & $0.153_{3}$ & $0.148_{8}$ & 790.3 & 768.9 \\
1.0 & $0.160_{2}$ & $0.155_{9}$ & 785.3 & 763.6 \\
\hline
\end{tabular}

Table 5 Thermal conductivity and density of 1-propanol2-butanol binary mixtures

\begin{tabular}{ccccc}
$\begin{array}{c}\text { 1-Propanol } \\
\text { mole } \\
\text { fraction }\end{array}$ & \multicolumn{2}{c}{$\tilde{\lambda}\left[\mathrm{W} \cdot \mathrm{m}^{-1} \cdot \mathrm{K}^{-1}\right]$} & \multicolumn{2}{c}{$\tilde{\rho}\left[\mathrm{kg} \cdot \mathrm{m}^{-3}\right]$} \\
$25.0^{\circ} \mathrm{C}$ & $50.0^{\circ} \mathrm{C}$ & $25.0^{\circ} \mathrm{C}$ & $50.0^{\circ} \mathrm{C}$ \\
\hline 0.0 & $\mathbf{0 . 1 3 3 _ { 5 }}$ & $0.129_{6}$ & 802.5 & 781.2 \\
0.2 & $0.137_{2}$ & $0.133_{1}$ & 802.3 & 781.0 \\
0.4 & $0.140_{2}$ & $0.135_{8}$ & 801.9 & 780.6 \\
0.6 & $0.143_{5}$ & $0.139_{6}$ & 801.4 & 780.2 \\
0.8 & $0.147_{5}$ & $0.142_{9}$ & 800.6 & 779.8 \\
1.0 & $0.149_{7}$ & $0.145_{6}$ & 799.3 & 778.8 \\
\hline
\end{tabular}

Table 6 Thermal conductivity and density of 2-butanol-1butanol binary mixtures

\begin{tabular}{ccccc}
$\begin{array}{c}\text { 2-Butanol } \\
\text { mole } \\
\text { fraction }\end{array}$ & \multicolumn{2}{c}{$\tilde{\lambda}\left[\mathrm{W} \cdot \mathrm{m}^{-1} \cdot \mathrm{K}^{-1}\right]$} & \multicolumn{2}{c}{$\tilde{\rho}\left[\mathrm{kg} \cdot \mathrm{m}^{-3}\right]$} \\
$25.0^{\circ} \mathrm{C}$ & $50.0^{\circ} \mathrm{C}$ & $25.0^{\circ} \mathrm{C}$ & $50.0^{\circ} \mathrm{C}$ \\
\hline 0.0 & $0.146_{3}$ & $0.142_{8}$ & 805.5 & 785.9 \\
0.2 & $0.144_{8}$ & $0.140_{8}$ & 805.2 & 785.2 \\
0.4 & $0.142_{2}$ & $0.137_{9}$ & 804.6 & 784.2 \\
0.6 & $0.139_{9}$ & $0.135_{6}$ & 803.9 & 783.0 \\
0.8 & $0.136_{9}$ & $0.133_{1}$ & 803.2 & 782.3 \\
1.0 & $0.133_{5}$ & $0.129_{6}$ & 802.5 & 781.2 \\
\hline
\end{tabular}

of liquids:

$$
\lambda=2 n \nu l C_{v} / N_{A}
$$

where $C_{v}$ is the constant-volume heat capacity, $\nu$ is the frequency of molecular vibration, $n$ is the number of molecules per unit area, $N_{A}$ is Avogadro's number, and $l$ is the distance between crystal lattice planes normal to the energy gradient. The value of $l$ is replaced by $2^{1 / 2} a / 2$ where $a$ is the distance between a molecule and its nearest neighbor. Further, $n$ is derived by assuming the presence of holes:

$$
n=\left(V_{0} / V\right) / a^{2}
$$

where $V_{0}$ denotes solid molar volume at the melting point and $V$ is liquid molar volume. Therefore, the working equation for the correlation of thermal conductivities can be derived from Eq. (4).

$$
\lambda=\sqrt{2}\left(V_{0} / V\right) C_{v} \nu / a N_{A}
$$

where

$$
a=2^{1 / 6}\left(V_{0} / N_{A}\right)^{1 / 3}
$$

\section{2 Frequency}

Assuming harmonic oscillation of the central molecule in the cell, the frequency can be derived $a^{5)}$

$$
\nu=\frac{1}{2 \pi \sqrt{M} / \bar{N}_{A}}=\left[\frac{2 z \varepsilon(T)}{r^{2} v^{* 2}}\left\{\frac{l(y)}{v^{* 2}}-2 m(y)\right\}\right]^{1 / 2}
$$


where

$$
\begin{gathered}
l(y)=\left(1+12 y+25.2 y^{2}+12 y^{3}+y^{4}\right)(1-y)^{-10}-1 \\
m(y)=(1+y)(1-y)^{-4}-1
\end{gathered}
$$

and

$$
\begin{gathered}
y=(r / a)^{2} \\
v^{*}=V_{0} / \sigma(T)^{3} N_{A} \\
z=12\left(V_{0} / V\right) \\
r=\{a-C \sigma(T)\} / 2
\end{gathered}
$$

where $C$ is a proportionality constant previously introduced ${ }^{13}$.

In the above derivation, the intermolecular potential energy function for polar substances is assumed to be given by Lennard-Jones (12-6) potential ${ }^{17)}$.

$$
\phi(r, T)=4 \varepsilon(T)\left\{\left(\frac{\sigma(T)}{r}\right)^{12}-\left(\frac{\sigma(T)}{r}\right)\right\}^{6}
$$

The potential parameters $\varepsilon(T)$ and $\sigma(T)$ are represented as a function of temperature $T$.

$$
\begin{gathered}
\varepsilon(T)=\varepsilon^{0}(1+\beta / T)^{2} \\
\sigma(T)=\sigma^{0}(1+\beta / T)^{-1 / 6}
\end{gathered}
$$

In essence, the term $(1+\beta / T)$ should be replaced by $\left(1+\mu^{4} / 6 k T \varepsilon^{0} \sigma^{06}+\mu^{2} \alpha / 2 \varepsilon^{0} \sigma^{06}\right)$ where $\alpha$ and $\mu$ are respectively the polarizability and dipole moment. As the term $\mu^{2} \alpha / 2 \varepsilon^{0} \sigma^{06}$ is much smaller than unity in general, the term $\left(1+\mu^{4} / 6 k T \varepsilon^{0} \sigma^{06}+\mu^{2} \alpha / 2 \varepsilon^{0} \sigma^{06}\right)$ is empirically approximated by a function of temperature $(1+\beta / T)$. Finally, with the introduction of Eq. (8) into Eq.(6), the correlation equation of thermal conductivity for a pure polar liquid is given by the following equation.

$$
\begin{aligned}
\lambda= & \frac{C_{v}}{2^{1 / 6} V_{0}^{1 / 3} \pi}\left\{\frac{z \varepsilon(T)}{M}\right\}^{1 / 2} \frac{1}{N_{A}^{1 / 6} r v^{*}} \\
& \times\left\{\frac{l(y)}{v^{* 2}}-2 m(y)\right\}^{1 / 2}\left(\frac{V_{0}}{V}\right)
\end{aligned}
$$

\section{3 Constant-volume heat capacity}

The constant-volume heat capacity of liquids can be correlated by a group contribution method within $1.2 \%$, as shown in a previous paper ${ }^{14}$. The values of $C_{v}$ for alcohols were given by the previous correlation.

\section{4 Solid molar volume at melting point}

In the present study, the solid molar volume at melting point $V_{0}$ is correlated with the van der Waals volume $V_{w}$. Sayegh et al. ${ }^{18}$ ) have reported that the liquid molar volume at $20^{\circ} \mathrm{C}$ can be represented by a linear function of $V_{w}$. Thereby, the present authors have attempted to correlate $V_{0}$ with $V_{w}$ for 35 organic compounds using the solid molar volume data at melting point shown in the literature ${ }^{1,11}$. The values of $V_{w}$ were obtained from a group contribution method of Bondir). The results are presented in Fig. 7. Parts of the data are plotted to avoid complication. From Fig. 7, one can obtain the following

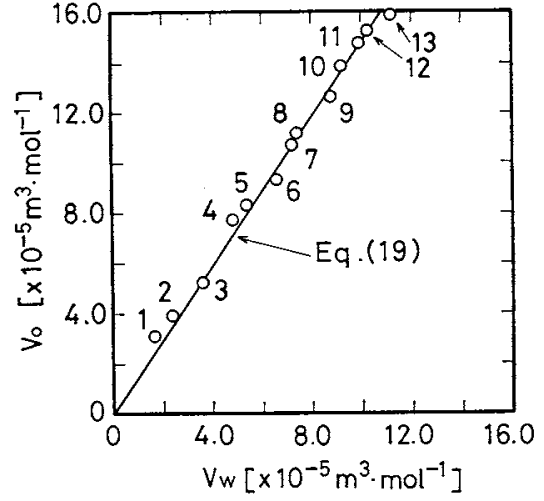

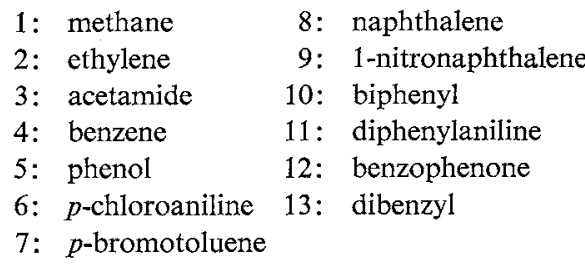

Fig. 7 Plots of $V_{0}$ vs. $V_{w}$

empirical equation.

$$
V_{0}=1.48 V_{w}
$$

\section{Correlation of Thermal Conductivities of Pure Alcohols}

Four unknown parameters $\varepsilon^{0}, \sigma^{0}, \beta$ and $C$ required in the calculation were determined to give the best fit with the experimental thermal conductivity of alcohols using the Simplex method ${ }^{8}$.

The best-fitted values of these parameters are listed in Table 7. Calculated thermal conductivities from these parameters are shown in Fig. 1. Thermal conductivities of pure alcohols can be correlated by Eq. (18) with good agreement. The discrepancy between calculated and experimental thermal conductivities does not exceed $1 \%$. The four parameters $\varepsilon^{0}, \sigma^{0}, \beta$, and $C$ can be correlated with Pitzer's acentric factor $\omega$ and Stiel's polar factor $\chi$ as shown in Fig. 8 . The values of $\omega$ and $\chi$ used were recalculated here based on the original definitions with the use of literature vapor pressure data ${ }^{16)}$ and are presented in Table 7. As shown in Fig. 8, they are well-expressed by the following quadratic equations.

$$
\begin{gathered}
\varepsilon^{0} / k T_{c}=-0.0386+0.2809 \omega+0.0112 \omega^{2} \\
\left\{\begin{array}{c}
\text { normal alcohol: } \\
\sigma^{03} N_{A} / V_{c}=0.6658-1.2250 \omega+0.7836 \omega^{2} \\
\text { branched alcohol: } \\
\sigma^{03} N_{A} / V_{c}=0.2016+0.3430 \omega-0.5554 \omega^{2} \\
C=0.4006+1.8669 \omega-2.6495 \omega^{2} \\
\beta / T_{c}=0.2008+0.5229 \chi+3.0587 \chi^{2}
\end{array}\right.
\end{gathered}
$$

The errors between experimental results and calculated values from Eqs. (18) and (20) to (24) are shown in Table 8. The average error for the ten 
Table 7 Physical properties and best-fitted values of parameters for alcohols

\begin{tabular}{|c|c|c|c|c|c|c|c|c|c|c|c|}
\hline No. & Alcohol & $\omega$ & $\chi$ & $T_{c}[\mathrm{~K}]^{* *}$ & $V_{c}\left[\mathrm{~m}^{3} \cdot \mathrm{mol}^{-1}\right]^{* *}$ & $\varepsilon^{0} / k T_{\varepsilon}$ & $\sigma^{03} N_{A} / V_{c}$ & $C$ & $\beta / T_{c}$ & $N$ & $\begin{array}{c}\text { Avg. error } \\
{[\%]^{*}}\end{array}$ \\
\hline 1 & Ethanol & 0.636 & 0.002 & 516.2 & $1.67 \times 10^{-4}$ & 0.1448 & 0.2054 & 0.5119 & 0.2017 & 8 & 0.10 \\
\hline 2 & 1-Propanol & 0.622 & -0.046 & 536.7 & $2.185 \times 10^{-4}$ & 0.1419 & 0.2063 & 0.5314 & 0.1834 & 10 & 0.12 \\
\hline 3 & 2-Propanol & 0.665 & -0.039 & 508.3 & $2.20 \times 10^{-4}$ & 0.1529 & 0.1840 & 0.4714 & 0.1854 & 7 & 0.37 \\
\hline 4 & 1-Butanol & 0.591 & -0.087 & 562.9 & $2.74 \times 10^{-4}$ & 0.1302 & 0.2150 & 0.5803 & 0.1792 & 10 & 0.30 \\
\hline 5 & 2-Butanol & 0.578 & -0.082 & 536.0 & $2.68 \times 10^{-4}$ & 0.1272 & 0.2148 & 0.5924 & 0.1782 & 10 & 0.24 \\
\hline 6 & $\begin{array}{l}\text { 2-Methyl-1- } \\
\text { propanol }\end{array}$ & 0.591 & -0.093 & 547.7 & $2.73 \times 10^{-4}$ & 0.1310 & 0.2093 & 0.5954 & 0.1794 & 10 & 0.20 \\
\hline 7 & 1-Pentanol & 0.590 & -0.059 & 586. & $3.26 \times 10^{-1}$ & 0.1310 & 0.2163 & 0.5756 & 0.1801 & 10 & 0.08 \\
\hline 8 & 2-Methyl-1- & & & & & & & & & & \\
\hline & butanol & 0.612 & -0.084 & 571. & $3.22 \times 10^{-4}$ & 0.1377 & 0.2040 & 0.5455 & 0.1771 & 10 & 0.12 \\
\hline 9 & 1-Hexanol & 0.647 & -0.054 & 610. & $3.81 \times 10^{-4}$ & 0.1475 & 0.2004 & 0.5041 & 0.1816 & 10 & 0.08 \\
\hline 10 & 1-Heptanol & 0.557 & -0.103 & 633. & $4.35 \times 10^{-4}$ & 0.1220 & 0.2267 & 0.6154 & 0.1792 & 10 & 0.11 \\
\hline
\end{tabular}

* Avg. error $=\left\{\sum\left|\lambda_{\text {expt1. }}-\lambda_{\text {ealed. }}\right| \times 100 / \lambda_{\text {expt1. }}\right\} / N ; N=$ number of data

** Values of $T_{c}$ and $V_{c}$ are cited from reference 16).
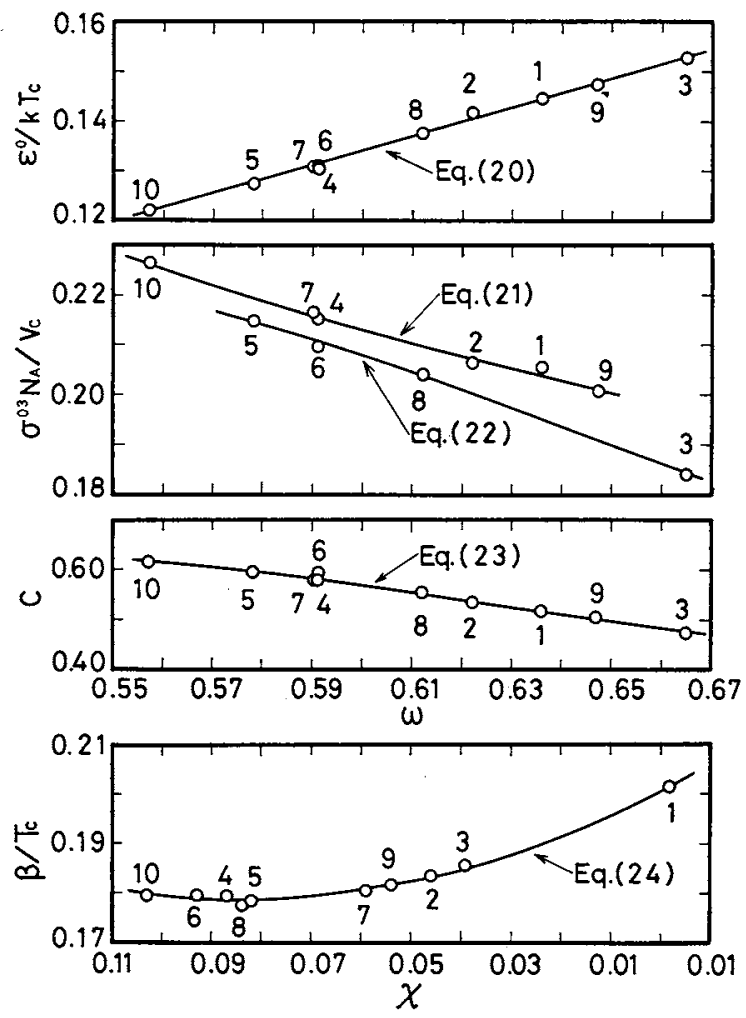

(Numbers are the same as in Table 7.)

Fig. 8 Correlation of parameters

alcohols under discussion is $2.3 \%$.

\section{Correlation of Thermal Conductivities of Liquid Mixtures}

Extending the above correlation method to binary liquid mixtures, Eq. (6) becomes

$$
\tilde{\lambda}=\sqrt{2}\left(\tilde{V}_{0} / \tilde{V}\right) \tilde{C}_{v} \tilde{\nu} / \tilde{a} N_{A}
$$

where $\tilde{V}_{0}, \tilde{V}, \tilde{C}_{v}, \tilde{\nu}$, and $\tilde{a}$ are average values for a liquid mixture with a given composition. On the basis of the concept of the two-fluid model, the frequency of a liquid mixture is given by the following equation.
Table 8 Average error between experimental results and calculated values from Eq. (18) and Eqs. (20) to (24)

\begin{tabular}{rlrc} 
No. & \multicolumn{1}{c}{ Alcohol } & $N$ & Error $[\%]^{*}$ \\
\hline 1 & Ethanol & 8 & -3.7 \\
2 & 1-Propanol & 10 & -0.8 \\
3 & 2-Propanol & 7 & 0.7 \\
4 & 1-Butanol & 10 & 1.9 \\
5 & 2-Butanol & 10 & -1.2 \\
6 & 2-Methyl-1-propanol & 10 & 6.4 \\
7 & 1-Pentanol & 10 & -1.5 \\
8 & 2-Methyl-1-butanol & 10 & -2.5 \\
9 & 1-Hexanol & 10 & 3.0 \\
10 & 1-Heptanol & 10 & -1.1 \\
& Average error** & & 2.3 \\
\hline
\end{tabular}

* Error $=\left\{\sum\left(\lambda_{\text {eated. }}-\lambda_{\text {exptr. }}\right) \times 100 / \lambda_{\text {exptr. }}\right\} / N$

** Average error $=\sum \mid$ Error $\mid / 10$

$N=$ number of data

$$
\tilde{\nu}=\sum_{i} x_{i} \nu_{(i)}
$$

where

$$
\nu_{(i)}=\frac{1}{2 \pi \sqrt{ }} \overline{\overline{M_{i}}} / \overline{N_{A}}\left[\frac{2 \tilde{z} \varepsilon(T)_{(i)}}{\tilde{r}^{2} \tilde{v}^{* 2}}\left\{\frac{l(\tilde{y})}{\tilde{v}^{* 2}}-2 m(\tilde{y})\right\}\right]^{1 / 2}
$$

The value of $\tilde{y}$ is obtained from Eq. (14) by using the following mixing rules:

$$
\begin{gathered}
\tilde{r}=\left\{\tilde{a}-\sum_{i} x_{i} C_{i} \sigma(T)_{i i}\right\} / 2 \\
\tilde{a}=2^{1 / 6}\left(\tilde{V}_{0} / N_{A}\right)^{1 / 3} \\
\tilde{V}_{0}=x_{1}^{2} V_{01}+2 x_{1} x_{2}\left(1-l_{12}\right) \sqrt{V_{01} V_{02}}+x_{2}^{2} V_{02}
\end{gathered}
$$

where $l_{12}$ is the characteristic parameter between molecules 1 and 2. The following averaging rules are further adopted in order to evaluate $\tilde{v}^{*}$ and $\tilde{z}$.

$$
\begin{gathered}
\tilde{v}^{*}=\tilde{V}_{0} /\left[N_{A}\left\{\sum_{i} x_{i} \sigma(T)_{i i}\right\}^{3}\right] \\
\tilde{z}=12\left(\tilde{V}_{0} / \tilde{V}\right)
\end{gathered}
$$

The molar volume of mixture $\tilde{V}$ can be obtained from

$$
\tilde{V}=\left(\sum_{i} M_{i} x_{i}\right) / \tilde{\rho}
$$

where $\tilde{\rho}$ is the density of the mixture and is available from Tables 3 to 6 . The values of $\varepsilon(T)_{(i)}$ can be pre- 
sented by

$$
\varepsilon(T)_{(i)}=\sum_{j} x_{j} \varepsilon(T)_{i j}
$$

and

$$
\varepsilon(T)_{i j}=\left(1-k_{i j}\right) \sqrt{\varepsilon(T)_{i i} \varepsilon(T)_{j j}}
$$

where $k_{i j}$ is the characteristic parameter between molecules $i$ and $j$. The average constant-volume heat capacity is approximated by

$$
\tilde{C}_{v}=\sum_{i} x_{i} C_{v i}
$$

The calculated thermal conductivities from Eq. (25) with the best-fitted values of $k_{12}$ and $l_{12}$ are shown for four alcohol binary mixtures by solid lines in Figs. 3 to 6 . The dotted lines are the calculated values with $k_{12}=0$ and $l_{12}=0$. Although relatively good agreement can be obtained with the introduction of either $k_{12}$ or $l_{12}$ alone, a more precise fit can be obtained if both $k_{12}$ and $l_{12}$ are introduced. The values of $k_{12}$ and $l_{12}$ seem to be independent of temperature.

\section{Conclusions}

The thermal conductivities of ten pure liquid alcohols and four of their binary mixtures were measured by use of a relative horizontal parallel-plate method under atmospheric pressure. Thermal conductivity measurements for pure alcohols were carried out at temperatures from 20 to $70^{\circ} \mathrm{C}$ and for binary mixtures at 25.0 and $50.0^{\circ} \mathrm{C}$.

To represent the thermal conductivities of alcohols, a correlation model previously proposed for nonpolar liquids has been successfully extended to liquid alcohols with the introduction of a new parameter for the polar effect. The values of the four parameters required in the calculation of thermal conductivities can be correlated with Pitzer's acentric factor and Stiel's polar factor. The present model is also ex-

\begin{tabular}{|c|c|c|c|}
\hline \multicolumn{4}{|c|}{ Nomenclature } \\
\hline$A, B$ & & coefficients in Eq. (3) & \\
\hline$a$ & & $\begin{array}{l}\text { distance between a molecule and its } \\
\text { neighbor }\end{array}$ & {$[\mathrm{m}]$} \\
\hline$C$ & $=$ & proportionality constant in Eq. (14) & {$[-]$} \\
\hline$C_{v}$ & $=$ & constant-volume heat capacity $\quad[\mathrm{J} \cdot \mathrm{K}$ & $\left.-1 \cdot \mathrm{mol}^{-1}\right]$ \\
\hline$d$ & $=$ & thickness of liquid sample & {$[\mathrm{m}]$} \\
\hline$d_{0}$ & $=$ & thickness of standard glass plate & {$[\mathrm{m}]$} \\
\hline$k$ & $=$ & Boltzmann's constant & {$\left[\mathrm{J} \cdot \mathrm{K}^{-1}\right]$} \\
\hline$k_{i j}$ & & $\begin{array}{l}\text { characteristic parameter between } \\
\text { molecules } i \text { and } j\end{array}$ & {$[-]$} \\
\hline$l$ & & $\begin{array}{l}\text { distance between crystal lattice planes } \\
\text { normal to the temperature gradient }\end{array}$ & {$[\mathrm{m}]$} \\
\hline$l_{12}$ & $=$ & $\begin{array}{l}\text { characteristic parameter between } \\
\text { molecules } 1 \text { and } 2\end{array}$ & {$[-]$} \\
\hline$M$ & $=$ & molecular weight & $\left.\mathrm{Kg} \cdot \mathrm{mol}^{-1}\right]$ \\
\hline$N$ & $=$ & number of data & {$[-]$} \\
\hline$N_{A}$ & $=$ & Avogadro's number & {$\left[\mathrm{mol}^{-1}\right]$} \\
\hline$n$ & $=$ & number of molecules per unit area & {$\left[\mathrm{m}^{-2}\right]$} \\
\hline
\end{tabular}
tended to alcohol mixtures by use of the two-fluid model with binary interaction parameters. $\langle$ Subscripts and Superscripts〉

$$
\begin{array}{ll}
c & =\text { critical value } \\
i, j & =\text { component } i \text { and } j \\
\sim & =\text { mixture property } \\
1,2 & =\text { component } 1 \text { and } 2
\end{array}
$$

\section{Literature Cited}

1) Block, H.: Z. Physik. Chem., 78, 385 (1912).

2) Bondi, A.: "Physical Properties of Molecular Crystals, Liquids, and Glasses", John Wiley \& Sons, New York (1967).

3) Eng. Sci. Data, Item No. 75024, Engineering Sciences Data Unit, London (1975).

4) Fukuchi, K., K. Ogiwara, S. Yonezawa and Y. Arai: Technology Reports of Kyushu Univ., 53, 187 (1980).

5) Hirschfelder, J. O., C. F. Curtiss and R. B. Bird: "Molecular Theory of Gases and Liquids", p. 295, John Wiley \& Sons, New York (1967).

6) Horrocks, J. M. and E. McLaughlin: Trans. Faraday Soc., 56, 206 (1960).

7) Jobst, W.: Int. J. Heat Mass Transfer, 7, 725 (1964).

8) Kagaku Kogaku Kyokai: "Kagaku Kogaku Programming Enshu', p. 136, Baifukan, Tokyo (1976).

9) idem: "Bussei Teisu", Vol. 2, p. 40, Maruzen, Tokyo (1964).

10) Mallan, G. M., M. S. Michaelian and F. J. Lockhart: $J$ Chem. Eng. Data, 17, 412 (1972).

11) Moelwyne-Huges, E. A.: "Physical Chemistry", 2nd ed., (1961) (translated into Japanese by Y. Miyahara, Baifukan, Tokyo (1967)).

12) Nagashima, A., Y. Murata and S. Takisawa: Nippon Kikai Gakkai Ronbunshu, 43, 2268 (1977).

13) Ogiwara, K., Y. Arai and S. Saito: Ind. Eng. Chem., Fundam, 19, 295 (1980).

14) idem: J. Chem. Eng. Japan, 14, 156 (1981).

15) Raal, J. D. and R. L. Rijsdijk: J. Chem. Eng. Data, 26, 351 (1981).

16) Reid, R. C., J. M. Prausnitz and T. K. Sherwood: "The 
Properties of Gases and Liquids", 3rd ed., McGraw-Hill, New York (1977).

17) Saito, S.: "Heikobussei Suisan no Kiso", p. 56, Baifukan, Tokyo (1980).

18) Sayegh, S. G. and J. H. Vera: Chem. Eng. J., 19, 1 (1980).

19) Touloukian, Y. S., P. E. Liley and S. C. Saxena: "Thermophysical Properties of Matter", Vol. 3, IFI/Plenum, New York (1970).
20) Watanabe, K., J. Yata and T. Minamiyama: Nippon Kikai Gakkaishi, 81, 1182 (1978).

21) Yaws, C. L., J. J. McGinley and P. N. Shah: Chem. Eng., Oct. 25, 127 (1976).

(Presented at the 46th Annual Meeting (Nagoya, April, 1981) and the 15th Autumn Meeting (Kanazawa, Oct., 1981) of The Soc. of Chem. Engrs., Japan.)

\title{
JET MIXING OF FLUIDS IN TANKS
}

\author{
TOSHIRo MARUYAMA, YUJI BAN AND TOKURo MIZUSHINA \\ Department of Chemical Enginieering, Kyoto University, Kyoto 606
}

\begin{abstract}
An experimental investigation was made of the mixing of liquids in a tank where the liquid jet was injected through a nozzle. The mixing time was defined as the time required to reduce the concentration variation within $1 \%$ of the mixed mean value and was measured by an impulse response. The circulation time was also obtained from the response curve.

It was found that in the circulation flow regime of mixing $\left(R e \geqq 3 \times 10^{4}\right)$ there exists an optimum nozzle depth for rapid mixing. It ranges from the liquid surface level to three-quarters of the liquid depth when the liquid depth is equal to the tank diameter, and is the mid-depth of the liquid when the liquid depth is smaller than the tank diameter. When the nozzle height is within onefourth of the tank diameter, it is efficient for rapid mixing to tilt the nozzle upwards enough to prevent the formation of a wall jet, which induces circulations of small variance of circulation time.
\end{abstract}

\section{Introduction}

In modern chemical processing units, it is common practice that liquids in a tank are circulated by drawing them through a pump and returning them to the tank through a pipe or nozzle for such purposes as homogenation of physical properties, prevention of stratification, prevention of deposition of suspended particles, and tank cleaning.

Figure 1 depicts diagrammatically the configuration and symbols of jet mixing in a tank. The situation chosen is jet injection through a nozzle attached to the side wall of a cylindrical tank. The external recirculation system consists of a pipeline and a pump. The volume of the external system is negligibly small in comparison with the volume of the contents of tank. The nozzle is directed across a diameter of the tank at an arbitrary height $h_{i}$ and an arbitrary elevation angle $\theta$. The purpose of this study is to make clear the geometrical condition for rapid mixing in the circulation flow regime of mixing on the basis of measured mixing characteristics and

\footnotetext{
Received November 4, 1981. Correspondence concerning this article should be addressed to T. Maruyama. Y. Ban is now with Asahi Chem. Ind. Co., Ltd., Kurashiki 710
}

mixing time.

The correlating equations of the mixing time have been proposed by Fossett and Prosser ${ }^{2)}$, Fox and $\mathrm{Gex}^{83}$, van de Vusse ${ }^{81}$ and Okita and Oyama ${ }^{51}$. Fossett and Prosser ${ }^{2)}$ assumed that the momentum of the jet was preserved in the tank and that the jet diameter and jet axis length at the termination point of mixing were equal to the tank diameter. They measured concentrations electrically by a pair of electrodes in a tank $(D=152.4 \mathrm{~cm}, H=25.7 \mathrm{~cm})$ and correlated the mixing time with Eq. (1) on the basis of the two assumptions.

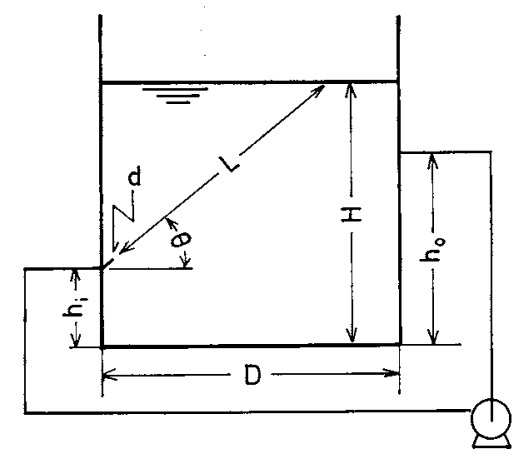

Fig. 1 Configuration and symbols of jet mixing in tank 